Ahrendt, I. 92

Alexiou, Ch. 98, 137

Arnold, W. 79, 81, 87, 98, 137

Baumann, C. 87

Bier, H. 129

Biermann, E. 149, 160

Böhnke, F. 81

Diller, G. 105

Fauser, C. 98

Fuhrmann, S. 98

Gall, V. 105

Ganzer, U. 129

Gloddek, B. 98

Haas, I. 129

Ilberg, C. von 105
Kau, R.J. 137

Kiefer, J. 105

Koch, U. 92

Koldovsky, P. 129

Kramer, J. 87

Kumazawa, H. 155

Kumazawa, T. 155

Lamm, K. 98

Lamprecht, J. 144

Lamprecht-Dinnesen, A. 115, 120

Löser, St. 144

Matulat, P. 115, 120

Morgenstern, C. 149

Neubert, W.J. 87

Niedermeyer, H.P. 87
Nishimoto, J. 155

Pfennigdorff, T. 105

Riebandt, M. 115, 120

Sánchez-Hanke, M. 92

Sandrieser, P. 120

Scherer, E. 81

Schultz, K.-D. 160

Schuster, M. 87

Schwaiger, M. 137

Seifert, E. 120

Spelsberg, A. 105

Ußmüller, J. 92

Werner, M. 137

Wesemeier, K. 87

Yamashita, T. 155

\title{
Subject Index Vol. 9, No. 3-4, 1999
}

Acoustic neurinoma 92

Allergic rhinitis 155

Amiodarone 149

Autoinjections 160

Basilar membrane 81

Central auditory processing disorder 115

Children 105

Cochlear implant(s) 105,120

Diode laser surgery 155

Dyslexia 115

Fibroblasts 129

Glucocorticoids 98

Growth inhibition 129

Head and neck 137

Hearing aids 105

- loss 105
Histopathology 92

Intravenous therapy 98

Localisation 144

Long-term results 120

Lymph node 137

Measles virus 87

Melanocytes 92

Mesenchymal-epithelial interactions 129

Morphometry 92

Multiple primary tumours 144

Münchhausen syndrome 160

Nasal endoscope 155

Otosclerosis 87

Parotidectomy 160

Perilymph 81, 87

Persistence 87
Personality disorders 160

PET 137

Phonological awareness 115

Sensorineural hearing loss 98

Smoke inhalation 144

Speech perception 120

- understanding 105

Spiral ganglion 92

Squamous cell carcinoma cell lines 129

Stapes footplate prosthesis 81

Thyroidectomy 149

Thyrotoxicosis 149

Time resolution 120

\section{KARGER \\ () 2000 S. Karger AG, Basel}

Fax + 41613061234

E-Mail karger@karger.ch

www. karger.com

Accessible online at:

www.karger.com/journals/orn 